\title{
Characterization and in vitro Evolution of Antibacterial Efficacy of Novel Hesperidin Microemulsion
}

\author{
Çinel Köksal Karayıldırım* \\ Department of Biology, Faculty of Science, Ege University, 35100, Izmir, Turkey \\ cinelbio@hotmail.com \\ *Corresponding author
}

Received: 28 June 2017

Accepted: 24 December 2017

DOI: $10.18466 /$ cbayarfbe. 370370

\begin{abstract}
Natural products used in the traditional systems of medicine exhibit a various and promising resource in human health. However, these products are often characterized for their chemical composition as well as mechanisms of action. Considering the bacterial infections play an important role in human diseases, it is necessary to develop new antibacterial herbal products. The aim of this study was to isolation and structural identification of hesperidin from Citrus sinensis L. and to formulate hesperidin loaded to water-in-oil (w/o) microemulsion as an inovative formulation for bactericidal treatment. This present study indicates that hesperidin microemulsion has antibacterial activity against various types of bacteria according to MIC method. All strains were showed logaritmic reduction. These findings indicated that the microemulsion as a drug carrier, especially hesperidin formulation, may be used as an effective antibacterial therapy.
\end{abstract}

Keywords - Citrus sinensis, Hesperidin, Antibacterial activity, Microemulsion, MIC

\section{Introduction}

In a worldwide, plant species are used as an alternative therapy and they are considered as potential source for development of new drugs [1]. According to World Health Organization (WHO) $80 \%$ of population in developing countries use plant origin pharmaceuticals [2]. Medicinal plants have been used for the treatment of various diseases such as infections, gastrointestinal ailments, reproductive and skeletal system problems [36]. Remarkable effects of medicinal plant materials indicated that they have bioactive substances mainly called as seconder metabolites [7]. They are primarily classified into alkaloids, terpenoids and phenolics whereas important and widely exploited groups of plants. Phenolic compounds are also common plant metabolites which are characterized bactericidal efficacy [8]. One of the largest and abundant class of phenolics is the flavonoids. Chemical complexity and biological activity of flavonoids enable wide range of their usage [9].

Hesperidin (Hsd) is a flavanon type glycoside which has been found mainly in Citrus fruits about 1000-5000 $\mathrm{mg} / \mathrm{kg}$ [10]. Naturally multifunctional hesperidin has a great variety of biopharmaceutical activities, e.g. anticancer, anti-inflammatory, antioxidant and antimicrobial [11-13]. Consequently, hesperidin is widely used in the clinical treatment of many diseases, and it also serve as a raw ingredient for different drugs in pharmaceutical industry.
It is important to develop novel plant origin drugs to improve the outcome for patients. The water solubility of herbal drugs has been improved by many techniques. These techniques consist of physical modification of drug molecule, the use of excipients and development of dosage forms.

Hesperidin was isolated from the Citrus sinensis L. and its chemical structure was elucidated by using NMR as a beginning of this study. The one of the purpose of this study was to assess the hesperidin microemulsion development, thus microemulsions are homogeneous dispersions of water-in oil or oil-in-water droplets stabilized by surfactants. Additionally, results indicated that the novel herbal microemulsion was effective against E. coli, S. epidermidis, B. cereus, E. faeclis, $S$. typhimurium, $K$. pnuemonie, $P$. aeruginosa. This study is allowed to acquire data about this prototype of new drug's antimicrobial potential as a therapeutic material.

\section{Materials and Methods}

\subsection{Chemicals and Reagents}

All chemicals used in extraction and isolation were supplied from Merck (Darmstadt, Germany) and used as received. Span 80 and Tween 80 were obtained from Merck (Darmstadt, Germany). Transcutol HP was received as a gift from Gattefosse (Nanterre, France). The following media were also used in MIC Test TSA (Tryptic Soy Agar, Merck, Germany), TSB-ST 
(Tryptone soya broth, Biomerieux ${ }^{\circledR}$, France), Diluent (MRTD, Biomerieux ${ }^{\circledR}$, France), Mueller-Hinton broth (Oxoid, UK), Gentamycin (Sigma Aldrich Chemical Co. St Louis, USA) was also used..

\subsection{Isolation of Hesperidin}

$200 \mathrm{~g}$ of fresh peel of Citrus sinensis L. was dried in shade, then grinded and extracted with methanol $(3 \times 1.5$ L) at room temperature. After filtration and evaporation under reduced pressure the methanolic extract (34.1 g) was suspended in water $(250 \mathrm{~mL})$ and partitioned successively with $n$-hexane $(3 \times 100 \mathrm{~mL})$, chloroform $(3 \times 100 \mathrm{~mL})$ and ethyl acetate $(3 \times 100 \mathrm{~mL})$. The evaporation of organic solvents in vacuu resulted in $1.2 \mathrm{~g}$ of $n$-hexane, $1.7 \mathrm{~g}$ of chloroform, and $2.9 \mathrm{~g}$ of ethyl acetate extracts.

The ethyl acetate extract (2.9 g) was subjected to open column chromatography using silica gel $(250 \mathrm{~g})$ employing chloroform:ethyl acetate $(9: 0.5,250 \mathrm{~mL} ; 9: 1$, $200 \mathrm{~mL} ; 8: 2,200 \mathrm{~mL}$ ) and hesperidin was obtained in chloroform:ethyl acetate (9:1) solvent system as pale yellow powder $\left(17 \mathrm{mg}\right.$ ). ${ }^{1} \mathrm{H}$ - and ${ }^{13} \mathrm{C}$-NMR (Spectrum 1 and 2) data were used to determine the structure of hesperidin [14] (Fig. 1).

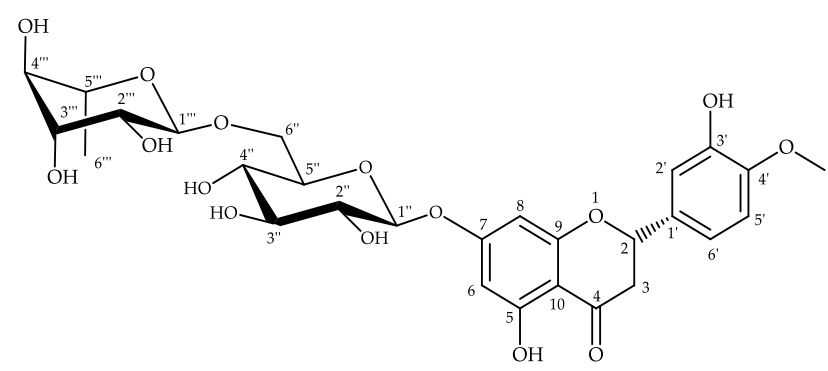

Figure 1. Structure of Hesperidin

\subsection{Preparation of Microemulsion}

In order to develop the microemulsion of hesperidin, water titration method at ambient temperature was conducted as described in our previous study [15]. The existence of microemulsion fields that form microemulsions under dilution and gentle agitation were identified from ternary phase diagrams of systems containing oil-surfactant (S)-cosurfactant $(\operatorname{coS})$. Oleique acide was selected as the oil phase. The effect of surfactants (the mixture of Span 80 and Tween 80 at 9.5:0.5 ratio) and cosurfactant (Transcutol HP) on the pseudo ternary phase diagram was systematically observed at room temperature. Distilled water was added dropwise to each clear oil and surfactants mixture with gentle stirring to allow equilibration. Following the addition of aliquot of water phase, the mixture was visually examined for transparency. Based on the results of pseudo ternary phase diagrams, one microemulsion was selected for further experiments. After that, hesperidine loaded microemulsion was prepared by containing $1 \mathrm{mg}$ FEX per $\mathrm{mL}$ with vortex.

\subsection{Determination of Antibacterial Activity Test Organisms}

In vitro antibacterial activity of hesperidin microemulsion was tested against four gram negative (Escherichia coli ATCC 10536, Pseudomonas aeroginosa ATCC 15442, Salmonella typhimurium ATCC 14028, Klebsiella pneumonie ATCC 13883) and four gram positive (Staphylococcus aureus ATCC 6538, Staphylococcus epidermidis ATCC 12228, Enterococcus faecalis ATCC 29212, Bacillus cereus ATCC 14579) bacterial strains.

E. coli, P. aeroginosa, S. typhimurium, S. aureus and E. faecalis were obtained from Biomerieux ${ }^{\circledR}$ (France) as a Bioball which contains a precise number of cells in a water soluble ball delivering unprecedented accuracy for quantitative microbiological quality control. $K$. pneumonie, S. epidermidis and B. cereus were purchased from Microbiologics ${ }^{\circledR}$ (USA) as the lyophilized microorganism pellet after two passages from the reference strain in a KWIK-STIK format.

\section{Minimum Inhibitory Concentration (MIC) Test}

Determination of MIC was carried out according to the microdilution method as described by NCCLS (2007) [16] with some modifications. Overnight bacterial suspension was adjusted to $0.5 \mathrm{McFarland}$ standards (Biomerieux, France) and diluted 1:100 (v/v) was used to inoculate Mueller-Hinton broth and incubated for $24 \mathrm{hrs}$ at $37 \mathrm{C}$. The serial dilutions of hesperidin were prepared in test tubes and then were added to the broth previously dispensed in 96 well microtiter plates. The final concentration of hesperidin in the wells ranged between 256 and $0.5 \mu \mathrm{g} / \mathrm{mL}$. The last well contained only $100 \mu \mathrm{L}$ broth and $10 \mu \mathrm{L}$ of bacterial suspension was used as negative control. All the plates were covered with a sterile plate sealer and incubated at $37{ }^{\circ} \mathrm{C}$ for $24 \mathrm{~h}$. The MIC was showed no visible growth and no turbidity when viewed against a black back ground. Samples from clear wells were sub-cultured on Mueller Hinton agar. Wells containing Gentamycin dilutions ranging between 128 and 0.25 were used as positive control All of the assays were performed in triplicate.

\section{Results \\ 3.1. Chemical Characterization of Hesperidin}

${ }^{1} \mathrm{H}-\mathrm{NMR}$ (DMSO- $\left.d_{6}, 400 \mathrm{MHz}\right) \delta(\mathrm{ppm}): 11.99(1 \mathrm{H}, \mathrm{br}$ s, 5-OH), $6.93(1 \mathrm{H}, \mathrm{d}, J=2.0 \mathrm{~Hz}, \mathrm{H}-2 '), 6.91(1 \mathrm{H}, J=8.0$ Hz, H-5'), 6.89 (1H, dd, J = 8.0, $\left.2.0 \mathrm{~Hz}, \mathrm{H}-6^{\prime}\right), 6.13$ (1H, $\mathrm{d}, J=2.0 \mathrm{~Hz}, \mathrm{H}-8), 6.11(1 \mathrm{H}, \mathrm{d}, J=2.0 \mathrm{~Hz}, \mathrm{H}-6), 5.46$ $(1 \mathrm{H}, \mathrm{dd}, J=11.0,5.0 \mathrm{~Hz}, \mathrm{H}-2), 4.97(1 \mathrm{H}, \mathrm{d}, J=7.2 \mathrm{~Hz}$, H-1"'), 4.54 (1H, br s, H-1), $3.78\left(3 \mathrm{H}, \mathrm{s}, 4-\mathrm{OCH}_{3}\right), 3.16-$ $3.64(6 \mathrm{H}, \mathrm{m}, \mathrm{H}-2 "$ to $\mathrm{H}-6 "), 3.16-3.64(3 \mathrm{H}, \mathrm{m}, \mathrm{H}-2$ "' to H-6"'), 3.08 (1H, dd, $J=17.0,11.0 \mathrm{~Hz}, \mathrm{H}-3 \mathrm{a}), 2.82(1 \mathrm{H}$, $\mathrm{dd}, \mathrm{J}=17.0,5.0 \mathrm{~Hz}, \mathrm{H}-3 \mathrm{~b}), 2.48(1 \mathrm{H}, \mathrm{d}, J=6.0 \mathrm{~Hz}, \mathrm{H}-$ 5), $1.09(3 \mathrm{H}, \mathrm{d}, J=6.0 \mathrm{~Hz}, \mathrm{H}-6) ;{ }^{13} \mathrm{C}$ NMR (DMSO- $d_{6}$, $100 \mathrm{MHz}) \delta$ (ppm): 197.38 (C-4), 165.56 (C-7), 163.47 (C-5), 162.95 (C-9), 148.39 (C-4'), 146.88 (C-3'), 131.39 (C-1'), 118.38 (C-6'), 114.57 (C-2'), 112.55 (C-5'), 
103.78 (C-10), 101.02 (C-1"), 99.92 (C-1"'), 96.86 (C-6), 96.00 (C-8), 78.79 (C-2), 76.72 (C-5"'), 75.98 (C-3"'), 73.43 (C-4"), 72.54 (C-2"'), 71.17 (C-4"'), 70.72 (C-3"), 70.06 (C-2"), 68.75 (C-5"), 66.48 (C-6"), 56.13 (4$\left.\mathrm{OCH}_{3}\right), 42.46$ (C-3), 18.25 (C-6"'). After comparing the results obtained to those of the literature, the structure of the isolated compound was identified as hesperidin $[14,17,18]$.

\subsection{Microemulsion Test Results}

Phase behavior investigation of these systems demonstrated the suitable approach to determine the water phase, oil phase, surfactant concentration, and cosurfactant concentration with which the transparent phase microemulsion system was formed [19]. The construction of phase diagram makes it easy to find out the concentration range of components for the existence range of microemulsions. The exact composition of oil, surfactant, cosurfactant and aqueous phase were showed in Table 1.

Table 1. The Composition of Microemulsion (wt. \%)

\begin{tabular}{|c|c|c|c|c|c|}
\hline Hsd & Oil & $\mathbf{S}_{1}$ & $\mathbf{S}_{\mathbf{2}}$ & $\mathbf{C o S}$ & $\begin{array}{c}\text { Wate } \\
\mathbf{r}\end{array}$ \\
$\begin{array}{c}\text { Formulatio } \\
\mathbf{n}\end{array}$ & 34.0 & 1.4 & 28.3 & 29.7 & 6.36 \\
& 5 & 9 & 1 & 9 & \\
\hline
\end{tabular}

\subsection{MIC Test Result}

It was demonstrated that hesperidin has inhibitory effects against the tested bacterial strains, with MICs ranging from 128 to $8 \mu \mathrm{g} / \mathrm{mL}$ indicating that hesperidin microemulsion formulation significantly inhibits bacterial growth (Table 2). Especially it showed strong activity on E. coli $(8 \mu \mathrm{g} / \mathrm{mL})$ and $E$. faecalis $(16 \mu \mathrm{g} / \mathrm{mL})$ with concentration equal to the standard antibiotic gentamicin.

Table 2. Antibacterial Activities of Hsd Microemulsion $(\mu \mathrm{g} / \mathrm{mL})$

\begin{tabular}{|c|c|c|}
\hline Strains & $\begin{array}{c}\text { Hsd } \\
\text { Microemulsion }\end{array}$ & Gentamicin \\
\hline $\begin{array}{c}\text { E. coli } \\
\text { ATCC } 10536\end{array}$ & 8 & 1.0 \\
\hline $\begin{array}{c}P . \text { aeroginosa } \\
\text { ATCC } 15442\end{array}$ & 128 & 1.0 \\
\hline $\begin{array}{c}\text { S. typhimurium } \\
\text { ATCC } 14028\end{array}$ & 128 & 1.0 \\
\hline $\begin{array}{c}\text { K. pneumonie } \\
\text { ATCC } 13883\end{array}$ & 128 & 4.0 \\
\hline $\begin{array}{c}\text { S. aureus } \\
\text { ATCC } 6538\end{array}$ & 32 & 1.0 \\
\hline $\begin{array}{c}\text { S. epidermidis } \\
\text { ATCC } 12228\end{array}$ & 32 & 1.0 \\
\hline $\begin{array}{c}\text { E. faecalis } \\
\text { ATCC } 29212\end{array}$ & 16 & 16.0 \\
\hline $\begin{array}{c}\text { B. cereus } \\
\text { ATCC } 14579\end{array}$ & 16 & 4.0 \\
\hline
\end{tabular}

\section{Discussion}

The World Health Organization (WHO) reported that global market supports herbal medicinal products [20]. Recent studies within the last decades have shown that the use of complementary and alternative medicine has increased Worldwide [21]. Therefore, it is important to develop effective and non-toxic novel herbal-based products for human welfare.

Herbal medicine production requires processing of the raw material to obtain the desired compound. [22]. Therefore quality control is required to maintain the effectiveness of the processed raw materials. Manufacturers of herbal medicine should ensure the integrity and maintain the efficiency/activity of all plant based products [23].

Hesperidin is a flavanone that is known for its antioxidant, anti-inflammatory and antibacterial properties [24]. Additionally, it is known to possess remarkable medicinal value and have been pharmacologically proved to be an antimicrobial, analgesic and immunomodulatory [25]. At the beginning of the isolation of hesperidin from Citrus sinensis and structural elucidation was carried out.

During the study, hesperidin microemulsion was conducted on phase diagram system according to water titration method. It is characterized as a dispersion consisting of oil, surfactant, cosurfactant and aqueous phase. This formulation has been used for various type of drug administration such as oral, dermal, intramuscular and intravenous. Moreover, particle size, transparency, low viscosity, thermal and thermodynamic stability over a wide range of $\mathrm{pH}$ 's and ionic environments and ease of preparation are considerable and important physicochemical advantages of microemulsions [26,27]. It was essential to find an appropriate method to exert the efficacy for acquiring ideal microemulsion formulation. The minimum inhibitor concentration test was used to analyse the antibacterial activity of hesperidin microemulsion against the bacteria $E$. coli, $P$. aeruginosa, $S$. aureus, $S$. typhimurium, $K$. pneumonie, $S$. epidermidis, E. faecalis, B. cereus which are one of the main causes of infections and diseases.

The results of this study indicate that the hesperidin microemulsion possess a relatively high antibacterial response while displaying novel plant origin drug capacity. Previously it has been shown that hesperidin has antibacterial efficacy against the gram-positive and gram-negative bacteria [28]. Besides it has been indicated that pretreatment with hesperidin could suppress infection-induced endotoxic shock in mice and reduce bacterial colonies during infection [29]. Regarding the evaluation of the humoral response, the present study showed that hesperidin microemulsion significantly decreased bacterial growth. The observed 
outcomes however confirm the anti-bacterial mechanisms of hesperidin.

This study provides evidence of innovative formation as an alternative antibacterial therapy of novel hesperidin microemulsion for drug delivery.

\section{Conflict of interest}

The authors have no conflicts of interest to declare.

\section{Acknowledgment}

The author is highly grateful to Dr. Evren GÜNDOĞDU and Dr. Tamer KARAYILDIRIM for their advice and suggestions during isolation of hesperidin and preparation of micro-emulsion.

\section{References}

1. Shakeri A., Amirhossein Sahebkar A., Behjat J., Melissa officinalis L. - A review of its traditional uses, phytochemistry and pharmacology, Journal of Ethnopharmacology, 2016, 188, 204228.

2. World Health Organization, WHO, Traditional Medicine Strategy Document 2003. Geneva, Switzerland.

3. Newman D.J. and Cragg G.M. Natural products as sources of new drugs over the last 25 years, Journal of Natural Products, 2007, 70, $3,461-477$

4. Moteetee A. and Kose L.S., Medicinal plants used in Lesotho for treatment of reproductive and post reproductive problems, Journal of Ethnopharmacology, 2016, 194, 827-849.

5. Omwenga E.O., Hensel A., Shitandi A., Goycoolea F.M. Ethnobotanical survey of traditionally used medicinal plants for infections of skin, gastrointestinal tract, urinary tract and the oral cavity in Borabu sub-county, Nyamira county, Kenya, Journal of Ethnopharmacology, 2015, 24, 508-514.

6. Muhammad A.A., Amir H.K., Muhammad A., Izatullah I Traditional uses of medicinal plants reported by the indigenous communities and local herbal practitioners of Bajaur Agency, Federally Administrated Tribal Areas, Pakistan, Journal of Ethnopharmacology, 2017, 198, 268-281.

7. İnce İ., Kayalar H., Elgin G., Köksal C.., Yavaşoğlu K.N.Ü. Antioxidant, Anti-inflammatory Activities and Acute Toxicity of the Polyherbal Formulation: Romix ${ }^{\circledR}$, Pharmaceutical Biology, 2012, 50, 720-726.

8. Mahmoudi S., Khali M., Benkhaled A., Benamirouche K., Baiti I Phenolic and flavonoid contents, antioxidant and antimicrobial activities of leaf extracts from ten Algerian Ficus carica L. Varieties, Asian Pacific Journal of Tropical Biomedicine, 2016, 6, 239-245.

9. Halfon B. Natural Products, Boğaziçi University Printhouse Lecture notes, 2005, (ISBN: 975.518.251.9). Turkey.

10. Robards, K. and Antolovich, M. Analytical Chemistry of Fruit Bioflavonoids A Review, Analyst, 1997, 122, 11R-34R.

11. Devi P.K., Rajavel T., Nabavi F.S., Setzer N.W., Ahmadi A., Mansouri K., Nabavi M.S. Hesperidin: A promising anticancer agent from nature, Industrial Crops and Products, 2015, 76, 582589.

12. Siddiqi A., Hasan K.S., Nafees S., Rashid S., Saidullah B., Sultan S. Chemopreventive efficacy of hesperidin against chemically induced nephrotoxicity and renal carcinogenesis via amelioration of oxidative stress and modulation of multiple molecular pathways, Experimental and Molecular Pathology, 2015, 99, 641-653.

13. Haghmorada D., Mahmoudi B.M., Salehipour Z., Jalayer Z., Brojenie M.A.A., Rastin M., Kokhaei P., Mahmoudi M. Hesperidin ameliorates immunological outcome and reduces neuroinflammation in the mouse model of multiple sclerosis, Journal of Neuroimmunology, 2017, 302, 23-33.

14. Hamdan D., El-Readi M.Z., Tahrani A., Herrmann F., Kaufmann D., Farrag N., El-Shazly A., Wink M. Chemical composition and biological activity of Citrus jambhiri Lush., Food Chemistry, 2011, 127, 394-403

15. Gündoğdu E., Karasulu Y.H., Köksal Ç. and Karasulu E. The novel oral imatinib microemulsions: physical properties, cytotoxicity activities and improved Caco-2 cell permeability, Journal of Microencapsulation, 2013, 30, 132-142.

16. National Committee for Clinical Laboratory Standards: Methods for Dilution Antimicrobial Susceptibility Tests for Bacteria that Grow Aerobically, Approved Standard - Eighth edition, 2007, NCCLS document M7-A6. NCCLS, Wayne, Pennsylvania.

17. Lahmer N., Belboukhari N., Cheriti A. and Sekkoum K. Hesperidin and hesperitin preparation and purification from Citrus sinensis peels. Der Pharma Chemica, 2015, 7, 1-4.

18. Akşit H., Çelik S. M., Şen Ö., Erenler R., Demirtaş İ., Telci İ. and Elmastaş M. Complete isolation and characterization of polar portion of mentha dumetorum water extract. Records of Natural Products, 2014, 8, 277-280.

19. Ghosh P.K., Majithiya R.J., Umrethia M.L., Murthy R.S. Design and development of microemulsion drug delivery system of acyclovir for improvement of oral bioavailability, American Association of Pharmaceutical Scientists Technology, 2006, 7(3), E172-E177.

20. World Health Organization, WHO, Traditional Medicine Strategy Document 2002-2005, 2002. 1346-1351, Geneva, Switzerland.

21. Türkmenoğlu P.F., Kutsal G.Y., Dolgun B.A., Diker Y., Baydar T. Evaluation of herbal product use and possible herbedrug interactions in Turkish elderly, Complementary Therapies in Clinical Practice, 2016, 23, 46-51.

22. Zhang J., Wider B., Shang H., Li X., Ernst E. Quality of herbal medicines: challenges and solutions, Complementary Therapies in Medicine, 2012, 20, 100-106.

23. Aziato L. and Odai N.A.P. Exploring the safety and clinical use of herbal medicine in the contemporary Ghanaian context: A descriptive qualitative study, Journal of Herbal Medicine, 2017, https://doi.org/10.1016/j.hermed.2016.11.002.

24. Yamamoto M., Jokura H., Hashizume K., et al. Hesperidin metabolite hesperetin-7- $O$-glucuronide, but not hesperetin-3'- $O$ glucuronide, exerts hypotensive, vasodilatory, and antiinflammatory activity of extract from Castanea sativa leaves, Fitoterapia, 2000, 71, 110-116.

25. Gar A., Garg S., Zaneveld L.J.D., Singla A.K. Chemistry and pharmacology of the citrus bioflavonoid hesperidin, Phytotherapy Research, 2001, 15, 655-669.

26. Wang J.J., Sung K.C., Hu O.Y., Yeh C.H., Fang J.Y. Submicron lipid emulsion as a drug delivery system for nalbuphine and its prodrugs, Journal of Controlled Release, 2006, 115, 140-149.

27. Cui J., Yu B., Zhao Y., Zhu W., Li H., Lou H., Zhai G. Enhancement of oral absorption of curcumin by self- 
microemulsifying drug delivery systems, International Journal of Pharmaceutics, 2009, 371, 148-155.

28. Basile A., Sorbo S., Giordano S., Ricciardi L., Ferrara S., Montesano D., Castaldo C.R., Vuotto M.L., Ferrara L. Antibacterial and allelopathic activity of extract from Castanea sativa leaves, Fitoterapia, 2000, 1, 110-116.
29. Kawaguchi K., Kikuchi S., Hasunuma R., Maruyama H., Yoshikawa T., Kumazawa Y. A citrus flavonoid hesperidin suppresses infection-induced endotoxin shock in mice, Biological and Pharmaceutical Bulletin, 2004, 27, 679-683

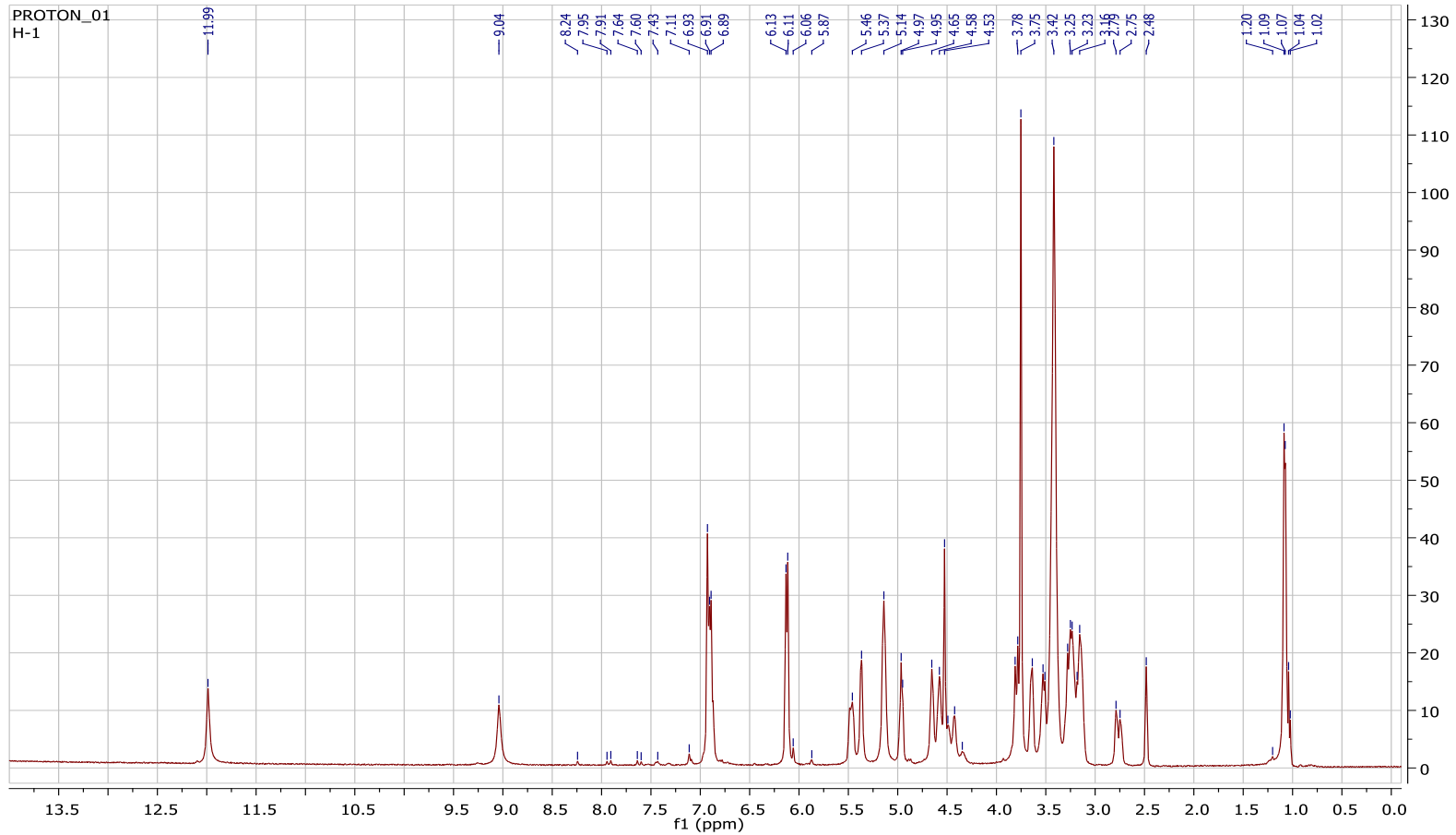

Spectrum 1. ${ }^{1} \mathrm{H}-\mathrm{NMR}$ Spectrum of Hesperidin (400 MHz, DMSO-d6)

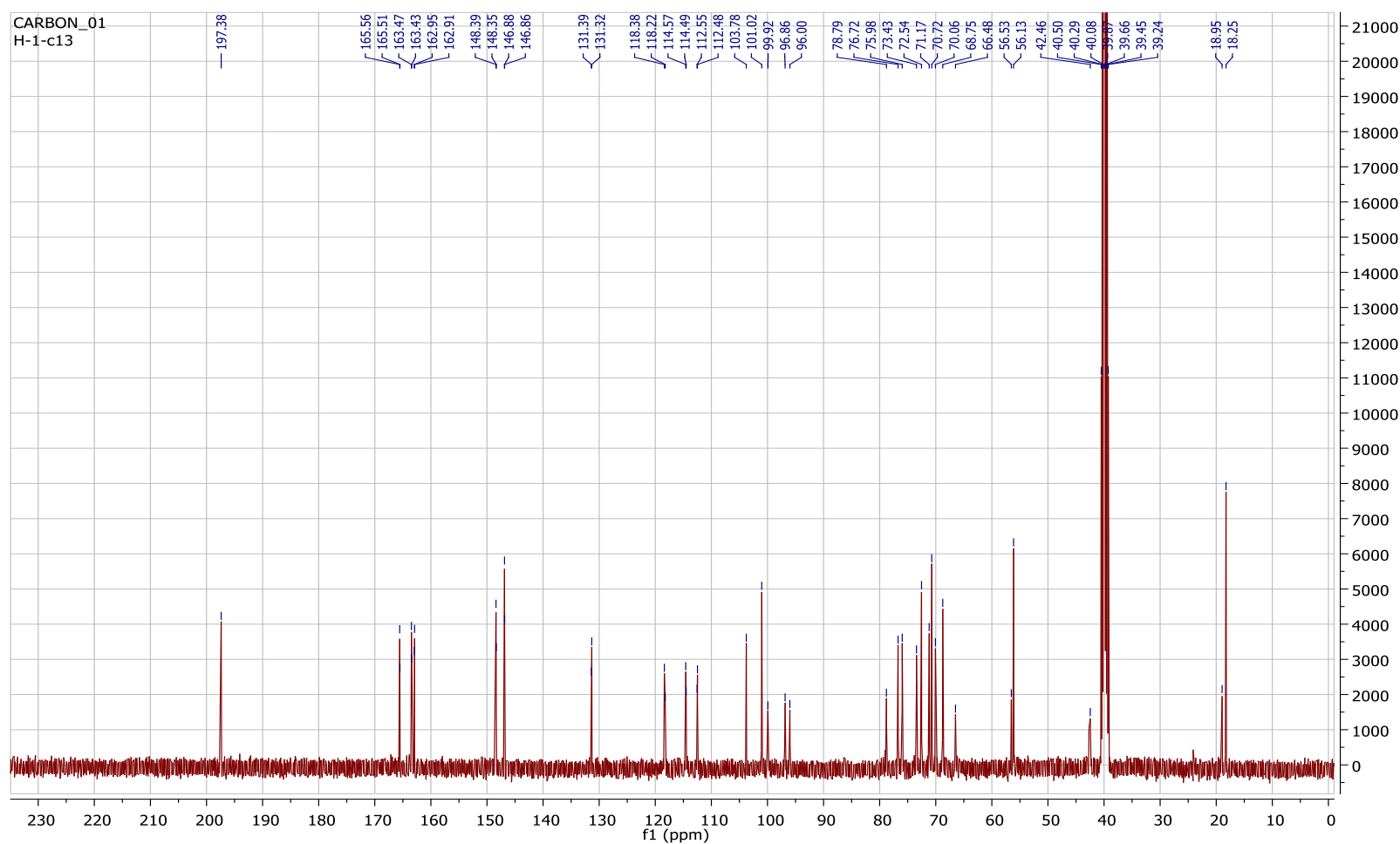

Spectrum 2. ${ }^{13} \mathrm{C}-\mathrm{NMR}$ Spectrum of Hesperidin (100 MHz, DMSO-d6) 